\title{
Bridging the perceptual gap: variations in crime perception of businesses at the neighborhood level
}

\author{
Valerie Spicer, Justin Song and Patricia Brantingham
}

\begin{abstract}
Current research on fear of crime reveals a recurrent theme of disorder in explanations of fear of crime and perceptions of security. This disorder is scalable, ranging from proximal cues associated with specific encounters between people or defined micro locations through to distal feelings of fear about areas, activity nodes, or major pathways. The research presented here compares two samples $(n=235)$ of businesses surveyed during the summer of 2012 in Grandview-Woodland, a diverse neighborhood, in the City of Vancouver, Canada. A visualization technique is presented to demonstrate how aggregate cognitive maps about perception of crime can be created and used by civic agencies when determining strategies aimed at reducing fear of crime. The results show that although both samples are taken from the same geographical neighborhood, their specific location within the community generates two very distinct perceptual patterns. Differences between the impact of proximal and distal cues on perception is explored. Other variations in perception are studied including differences between males and females, business owners and employees and those who have been victims of property crime versus personal crime. The results are presented and future research directions discussed.
\end{abstract}

Keywords: Business security; Fear of crime; Disorder; Cognitive

\section{Introduction}

Business communities are unique in their experience of the urban domain. They occupy both social and physical spaces that present different opportunities for victimization. Understanding these dynamics and implementing crime prevention strategies that mitigate victimization can help to foster healthier business communities. In particular, the perception of crime and disorder can instigate adverse feelings and generate fear thus altering how people behave in the urban domain potentially increasing subsequent victimization. The research presented in this paper aims to discover perceptual variations within a business community located in Grandview-Woodland, Vancouver, Canada.

While there are numerous factors that impact perception of crime such as age, gender, ethnicity, social economic status and level of education, the spatial dynamics of perception of crime can elicit new information about this phenomenon [1-4]. In particular, spatially locating perception of crime within business communities can be done using a mapping technique in which either employees

\footnotetext{
* Correspondence: vspicer@sfu.ca

Institute of Canadian Research Studies, Simon Fraser University, Burnaby, BC, Canada
}

or business owners working in a particular neighborhood are presented with an area map, and then asked to indicate the area(s) where they perceive there is a higher level of crime. Precision in defining specific places depends on multiple factors including the size of the study area and the individual's relative knowledge of local problems. Visualizing this geographical information can improve clarity and assist civic agencies and urban planners to enhance security plans thus assisting business communities in improving safety within the neighborhood.

Public disorder generates environmental cues that impact individuals when navigating their environment in particular at the pedestrian level. Studies on disorder such as those conducted under the Broken Windows theory have shown how individuals within urban communities are affected by public disorder [5-8]. Disorder encompasses both the physical and social manifestations of human behavior in the urban environment that are generally perceived as problematic. Studies have also shown how markers of disorder are both linked to fear and the perception of crime and can therefore influence pedestrian behavior [8-15]. Individuals in vehicles experience the environment differently depending on their knowledge of an 
area and the disorder cues that are impactful to individuals in vehicles are scalable to those experienced by pedestrians [13]. For example discarded syringes or condoms can be seen by pedestrians, but not by vehicle commuters. For pedestrians, tpublic disorder cues can act as a warning to crime problems such as public drug use, drug trafficking and solicitation.

Distal and proximal perception can be used to analyze the spatial distribution of perception of crime in the urban domain [16]. While these terms can describe the actual physical distance, they can be expanded and used to further explain proximal experiences of disorder, such as aggressive panhandlers outside the respondent's business, and the impact of distal landmarks such as mass transportation hubs. From a perception of crime and disorder perspective, proximal perception would be varied the individual level and dependent on personal experiences and location of experiences, whereas distal perception in the aggregate may form very structured patterns centered on known areas and landmarks.

No published research explores the mapping of perception of crime and disorder in the business community. Geographic information systems (GIS) are an effective method of visualizing a particular problem $[11,12,17,18]$. From a theoretical perspective, problem exploration through detailed visualization can lead to a better comprehension of the core elements that formulate a particular situation. Hotspot mapping that identifies concentrations of crime are usually represented using Kernel Density Smoothing to transform address level data to surface data. This technique has been used extensively in the policing world, yet it has almost uniquely been applied to reported crime data [19].

On the other hand, the mapping of crime perception may yield promising results [20]. In particular, business communities can benefit from this type of exploration because it helps to expose local dynamics and problems related to perceptions of security within the specific context of businesses. This paper explores a community survey approach and a visualization technique that can be used to analyze composite fear maps generated from drawings such as those shown in the following figures. This paper also presents a theoretical framework grounded in environmental criminology for the cognitive maps of fear produced by business owners and employees.

\section{Theoretical orientations}

Environmental criminology concerns itself with the everyday effect of the urban environment on the people who populate it. Perception of crime and security can be explored using principles from environmental criminology that are most often applied to criminal activity and events. The following theories are most often used to explain perception of crime and feelings of security within the analysis of space and time [21]:

- Routine Activity Theory

- Rational Choice Theory

- Geometry of Crime

- Pattern Theory

\section{Routine activity theory}

The Routine Activity Theory suggests the minimal elements for a criminal event to occur are a motivated offender, a suitable target and a non-capable guardian, but the inclusion of these elements does not mean a crime will always occur [22]. Furthermore both motivated and unmotivated individuals may commit crimes depending on the situation.

Within the context of perception of crime, this theory can be used to explain both perception of crime and feelings of security: individuals conduct their daily routines and during these activities, they are presented with situations where there is a perceived motivated offender and a lack of capable guardianship. The interaction of the three elements that form the Routine Activity Theory (victim - offender - location) can trigger a crime occurrence, but also create a fearful situation.

The temporal aspect of human movement is of particular importance because certain activities have to occur at a certain time and through a defined space. This is especially true within business communities where owners and employees have to commute to a designated place at a defined time. When locked into certain routes and times, individuals may feel more vulnerable within their environment [10]. When mass transportation is part of these movement patterns, the relationship between the transit system and the urban domain surrounding this system can create complex urban dynamics [12,23].

From the routine activity perspective, perception of crime at the aggregate level will occur where there is an intersection between human movement patterns in the urban domain, reduced guardianship and increased public display of criminality. This is both location and time specific as this theory includes the temporal dimension as the intersection of the three elements must occur in both a geographical place, and in a temporal space [22].

Furthermore, businesses owners and employees can play both the role of capable guardian and at the same time supply suitable targets in the environment. Therefore, these individuals are likely very attuned to the daily routines of neighborhoods as business owners and employees form an integral part of these routines and can also interrupt or intercept the routines that trigger crime occurrences.

\section{Rational choice theory}

The Rational Choice Theory assumes that individuals are rational and a decision-making process occurs prior to the 
commission of an offence. When individuals find themselves in a position to commit a crime, they will weigh the situation, considering both the potential risks associated with the act and the benefits resulting from the act [24].

This theory can be reversed and applied to people operating in the urban domain and who are making choices about activities and the potential victimization related to these choices. When presented with alternatives, the person in the potential victim position relies upon rational choice. There is a choice impasse when people are locked into a route and cannot make a rational decision to practice avoidant behavior [10]. These would be situations where the person engaged in the activity, is aware of the potential ramifications of his or her actions, but has few choices in relation the chosen activity. The individual in fact, is locked into a choice where crime avoidance is difficult and where victimization is probable. Mass transportation hubs are a good example of a choice impasse because people are reliant on this form of transportation and quite often do not have a viable alternative $[4,25]$. Therefore, they are locked into going to a very specific area even though they may be fully aware of potential victimization.

Within the business community, owners and employees are locked into many circumstances both temporally and geographically. The location of businesses determined by client base, and there are other factors some of which beyond their control such as problem premises near by or macro urban planning decisions that impact micro business communities. Owners and employees are guided by temporal patterns usually occupying regular business hours thus forecasting potential victimization. These factors are imbedded in individual decision making processes that guide how these individuals behave and perceive their environment.

\section{Geometry of crime}

Geometry of Crime Theory is based on human geography where decision-making about criminal offending is related to urban spatial dimensions. The environment produces cues that offenders pick up on and translate into perceived opportunities $[21,26]$. Offender movement patterns should not be assumed to differ considerably from the movement of the non-criminal population [27]. At the aggregate level, crime will be concentrated in locations where there is a convergence of environmental factors that relate to the general movement of offenders with the availability of suitable targets [28].

This theory can be applied to the perception of crime. Individuals in society have activities bringing them from one location to another. As people go through daily routines they develop an activity space that is related to an awareness space. However, rather than concentrating on perceived opportunities for the commission of a crime, they will develop an awareness around perceived opportunities for victimization. At the aggregate level, cues that generate the perception of crime may emanate more strongly in some areas and be linked to very specific displays of criminality and disorder.

Business owners and employees can be particularly attuned to perceived opportunities for victimization. For example, they may know and recognize prolific shoplifters operating in the area and be scanning customers looking for these individuals. Indeed, they are often in possession of viable targets and by virtue of this role are placed between potential offenders and their targets. As such, they can become more perceptive of cues in the environment that attract potential offenders. Their perception of the environment, especially near their place of employment is likely more intense and detailed as it may serve as a protective mechanism against victimization.

\section{Crime pattern theory}

The offender's awareness space is a geographical area surrounding travel paths that go between places such as a home, work or entertainment locations [21]. As the offender travels from place to place, they receive cues from the environment assisting them in the identification of suitable targets [28]. Offenders build an offending template taking into account these factors and eventually, this template stabilizes and becomes fixed, therefore leading to the predictability of offending patterns [28].

This theory can be inversed and applied to the perception of crime and rather than developing crime templates, individuals who act in a protective manner develop safety templates [20]. The term safety template is defined here as a new concept based on the concept of crime template formulated in Crime Pattern Theory. While a crime template is linked to the awareness space of a specific offender and used in criminal offending, individuals who navigate the urban domain and want to avoid victimization form safety templates [20].

Individuals in urban places travel from one location to the next in their daily routines and create awareness spaces around these travel paths. They will read cues in the environment and develop cognitive maps that include the information emitted from the environment. Feelings of safety and security will vary throughout the course of their travels depending on the cues they receive and how these relate to the locations they are attending. Over time, these cues will form fixed safety templates with some predictable cues and others linked to specific places or activities [20]. Within the safety template individuals will have both distal and proximal experiences with crime and disorder that will tie into their perception of crime. Distal experience will centered on areas where crime and disorder are more likely occur, whereas proximal experiences are individualized and defined through daily routines. 
Business owners and employees often have regular travel patterns to and from their work environment. They can also have a strong sense of their micro work environment. As these patterns evolve, feelings of safety in the workplace can be liked to a workplace safety template and new or different cues an indication of potential victimization.

\section{Summary of theory}

These four theories help define how perception of crime and feelings of security are displayed in the geographical urban space. While at the aggregate level there exists generalized patterns of perception within the urban domain, subcategories of individuals will experience the environment differently as the places where they reside, operate businesses or travel to work may vary significantly from the norm. Understanding these variations in perception and fear of crime can improve crime control techniques and assist in urban planning decisions [29]. Therefore, determining the specific perceptual dynamics of subcategories of individuals within the business community can assist in enhancing feelings of security in the urban domain. Within the business community, these theories help to understand the unique perceptual patterns of these individuals.

\section{Research study}

\section{Survey instrument}

The instrument used for this business survey was originally developed and implemented in 1997 by the GrandviewWoodland Community Policing Centre (GWCPC), located in Grandview-Woodland, Vancouver, Canada. The purpose of this survey is to gauge local perception of disorder problems occurring in the neighborhood and how this relates to perception of crime. The survey is designed so it could be filled out in a short amount of time. Therefore subjects can be polled on the street, in parks, at community events and business owners and employees with limited time would also be compelled to complete it. On the front of the survey, there are 30 questions about quality of life issues in the neighborhood varying from significant disorder problems such as aggressive panhandling to issues likely considered positive community attributes such as mural and outside café seating [20].

The back of the survey contains general demographic questions such as age, gender, location of residence as well as questions about victimization. At the bottom of this page, a map is included and respondents asked to circle the area on the map where they feel there is the highest level of crime. This survey instrument was implemented on several occasions including three times in Grandview-Woodland (1997-2007 - 2010). The 1997 and 2007 version of this survey remained identical as the purpose was to gauge differences that occurred in this 10 year period. The 2010 survey instrument was modified to include current issues affecting the neighborhood as reported to the GWCPC. The business survey instrument that was implement in this study utilized a similar format and the questions modified to reflect the business perspective as reported to the GWCPC.

The instrument was also modified to represent the needs of three other Vancouver communities and subsequently implemented. The survey results have guided community policing efforts and civic decisions in these neighborhoods [20].

\section{Survey implementation}

In 2012, the GWCPC wanted to obtain more detailed information on the business community in the GrandviewWoodland neighborhood so that specific programming could be develop to address their safety and security needs. The survey instrument was the same as the previous implementations containing 30 questions on the front, and demographics with a mapping component on the reverse. This business survey was distributed to every business in the study area. Figure 1 shows the study area. It is $4 \mathrm{~km}$ from the centre of the study area to downtown Vancouver.

The Grandview-Woodland neighborhood is 448 hectares large and contains a mix of land use including residential single family and multiple dwelling, industrial and commercial. The neighborhood is anchored by Commercial Drive where there are multiple shops, cafés, restaurants and pubs. There is a community center in the middle of this neighborhood and at the time it was built, was one of North America's largest facilities containing a high school, elementary school, library, and recreation center designed to accommodate the very mixed population in this area. This community center is adjacent to Grandview Park that covers a one block area and is a focal point. The southern part of this neighborhood contains the largest public transit station in British Columbia where two A Skytrain routes connect and funnel into cross-town buses. The Skytrain is a light rapid metro system that is mostly above ground and elevated servicing the metro Vancouver region. The northern part of Grandview-Woodland is predominantly industrial.

The composition of this neighborhood creates two distinct business communities within the same geographical area. The first community is located on Commercial Drive. This area attracts people to businesses for entertainment and shopping, and is used by both local residents and people coming to the area from elsewhere in the city. The second business community is located off Commercial Drive with most business in the northern section of the study area. This business community is more industrial based offering specialized services. The survey was implemented with the intent to target these two distinct business communities. Half the sample was taken from businesses located on Commercial Drive. The other half 


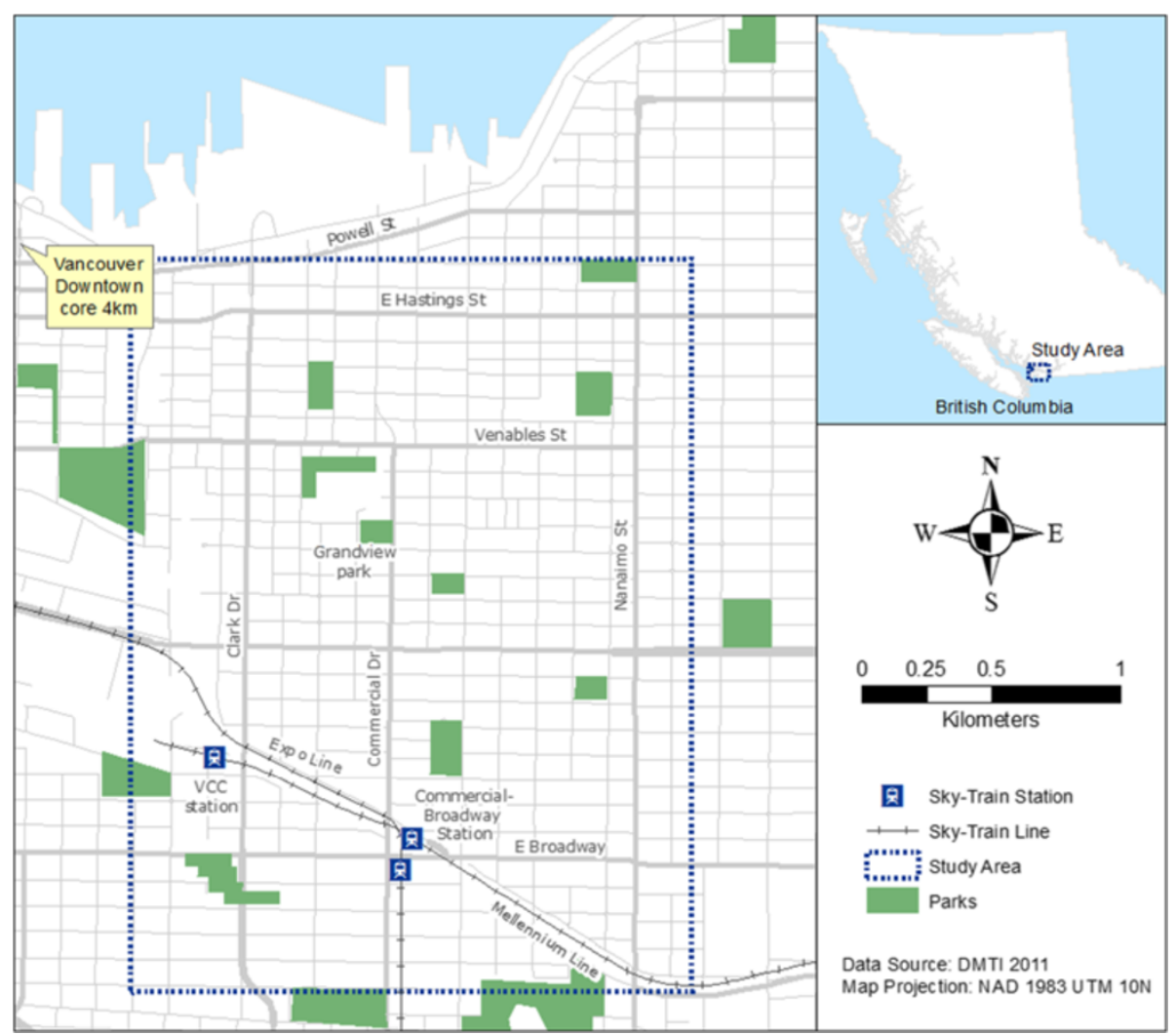

Figure 1 Study area - Grandview-Woodland.

was taken from businesses located off Commercial Drive. Businesses included in the study were street accessible and open to the general public such as grocery stores, specialty shops, pubs, cafes and restaurants.

Surveys were hand delivered by a GWCPC volunteer to every business located in the study area. This occurred during regular business hours from Monday to Friday between 9:00 AM and 5:00 PM. The completed surveys were collected a week later. Businesses that did not complete their survey were given an additional three days. This process occurred over two months (July and August) during the summer of 2012. Respondents were asked to complete this two-page survey that included 30 questions about crime and disorder in the neighborhood on the front page, demographical information on the second page, with a map of the study area where respondents were asked to circle the area they felt had the most crime.

As a result, 236 surveys were delivered with 99 completed surveys collected from Commercial Drive, 135 completed surveys collected from businesses off Commercial Drive. Two surveys that were delivered were not returned. This means that of the 236 surveys delivered and 234 were completed. This represents a $99.1 \%$ completion rate with 99 surveys in this study collected from the business community on Commercial Drive and 134 from businesses off Commercial Drive. The perception of crime mapping data from the surveys in this study is analyzed and presented in this paper.

\section{Perceptual business data and GIS analysis}

The completed surveys were analyzed and those with a completed map extracted from the sample. There were 47 crime perception maps completed by businesses located on Commercial Drive and 49 crime perception maps completed by businesses located elsewhere in the study area. The polygons drawn on the maps were manually entered and digitized using ArcGIS.

The polygons where then run through the raster function using a program loop to maximize this process. This program loop is described in Figure 2. Through this process the polygons were divided into rasters 10 by 10 meters squares. The raster function was selected as the most precise way to transcribe the drawn polygons into an analytical method of visualization. The 10 by 10 meter size was selected because it is small enough to capture both the smallest drawn polygons while at the same time providing incremental variation at the aggregate level when multiple polygons are overlapped. 


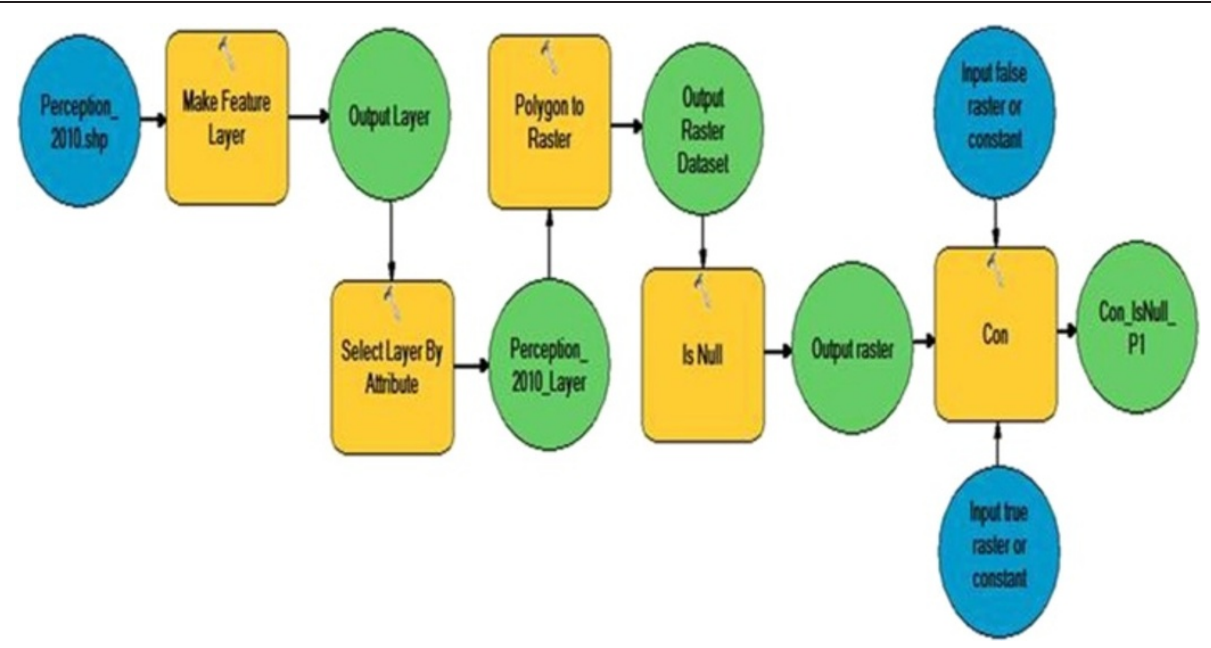

Figure 2 Raster program loop diagram.

\section{Results}

\section{Perceptual business maps}

The survey was implemented over a two-month period, July and August 2012. This lag in the survey implementation occurred as a result of the systematic hand delivery process through a trained volunteer. The goal was to obtain a high survey retrieval rate, which in this study is $99.1 \%$ of surveys delivered were collected. This time lag may impact results as experiences of crime and disorder will have varied throughout the study period.

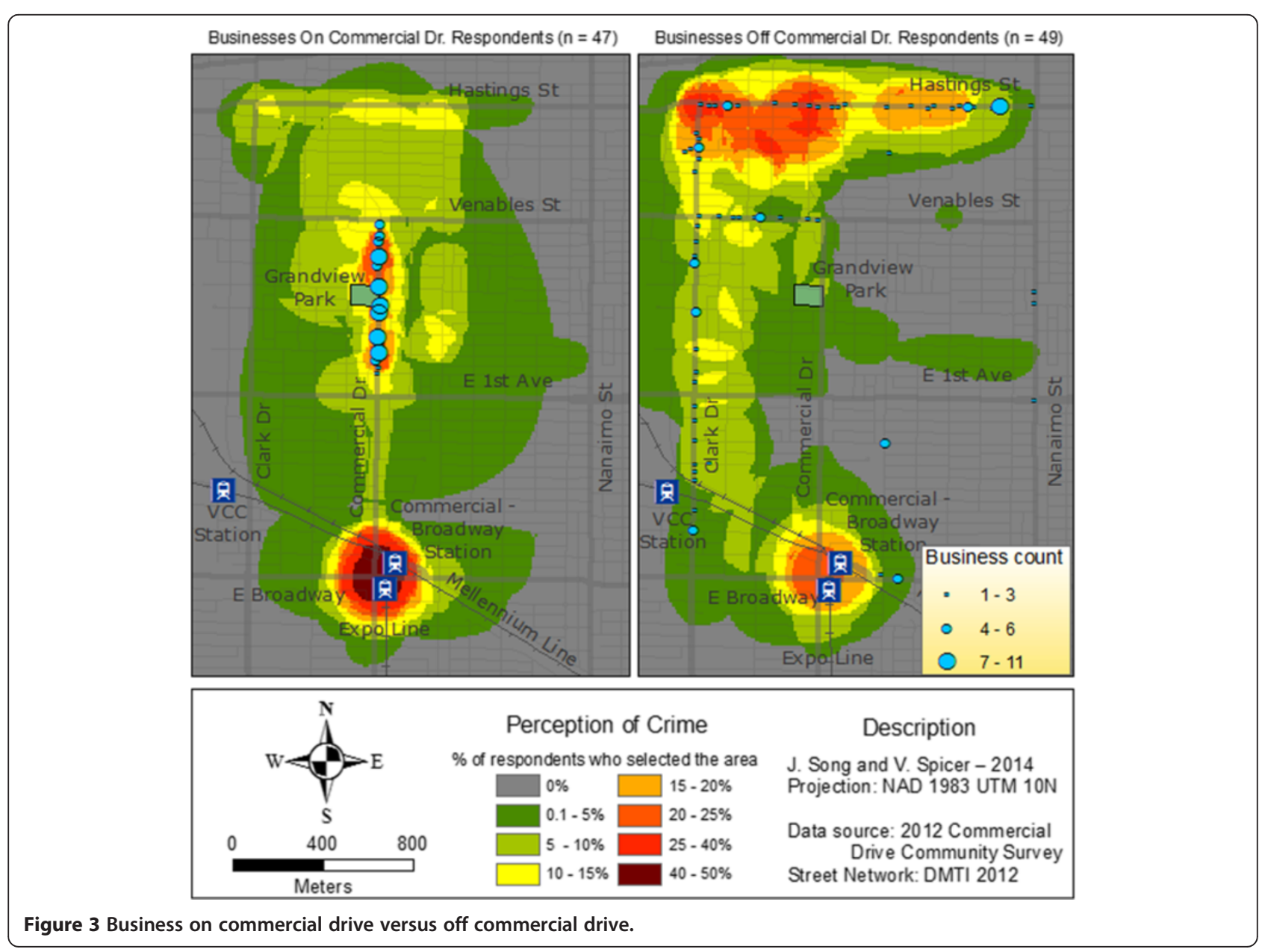


However, it should be noted that during this study period many factors remained consistent including the seasonal impact on street life, crime and disorder.

The two perceptual maps represented in Figure 3 show very distinct patterns. This first perceptual map compares the cognitive maps from businesses on Commercial Drive to businesses located off Commercial Drive. The average distance between the businesses on Commercial Drive to the Skytrain station is 1195 meters whereas this distance between businesses off Commercial Drive and the Skytrain station is 1518 meters. The average distance to the Skytrain station is of importance to this study because results from previous studies using this survey instrument show a significant hotspot around this station [27]. Therefore this station may have greater impact on the businesses that are more closely linked to this place. In particular, the businesses on Commercial Drive are directly tied to this location as this street extends to the intersection where the Skytrain station is located.

In Figure 3, two hotspots emerge in this map of businesses located on Commercial Drive. The first hotspot is located where the majority of surveyed businesses are located. The second hotspot is located at the south end of the study area and is substantially more pronounced with over $40 \%$ of respondents selecting an area covering 43,800 square meters. This area contains a mass transportation hub that connects two Skytrain lines and feeds express buses that travel along a major thoroughfare that bisects Vancouver. Commercial Drive is pedestrian oriented where public disorder is more prominent both the street activities and the influence on the Skytrain station impact perception of crime for these businesses.

The businesses off Commercial Drive display a significantly different perceptual pattern and select a very different area. Unlike businesses located on Commercial Drive, the focus is less concentrated at the south end of the study area where the major transportation hub is located. Rather, these businesses select a more diffused area located in the northwest sector. This is an area that is predominantly industrial where there are fewer walk-in shops and residences. These businesses are less affected by the residual effect of the Skytrain area and more aware of the potential crime problems relating to the industrial section of the study area.

The average surface area of the drawn polygons for businesses on Commercial Drive is 197,366 square meters

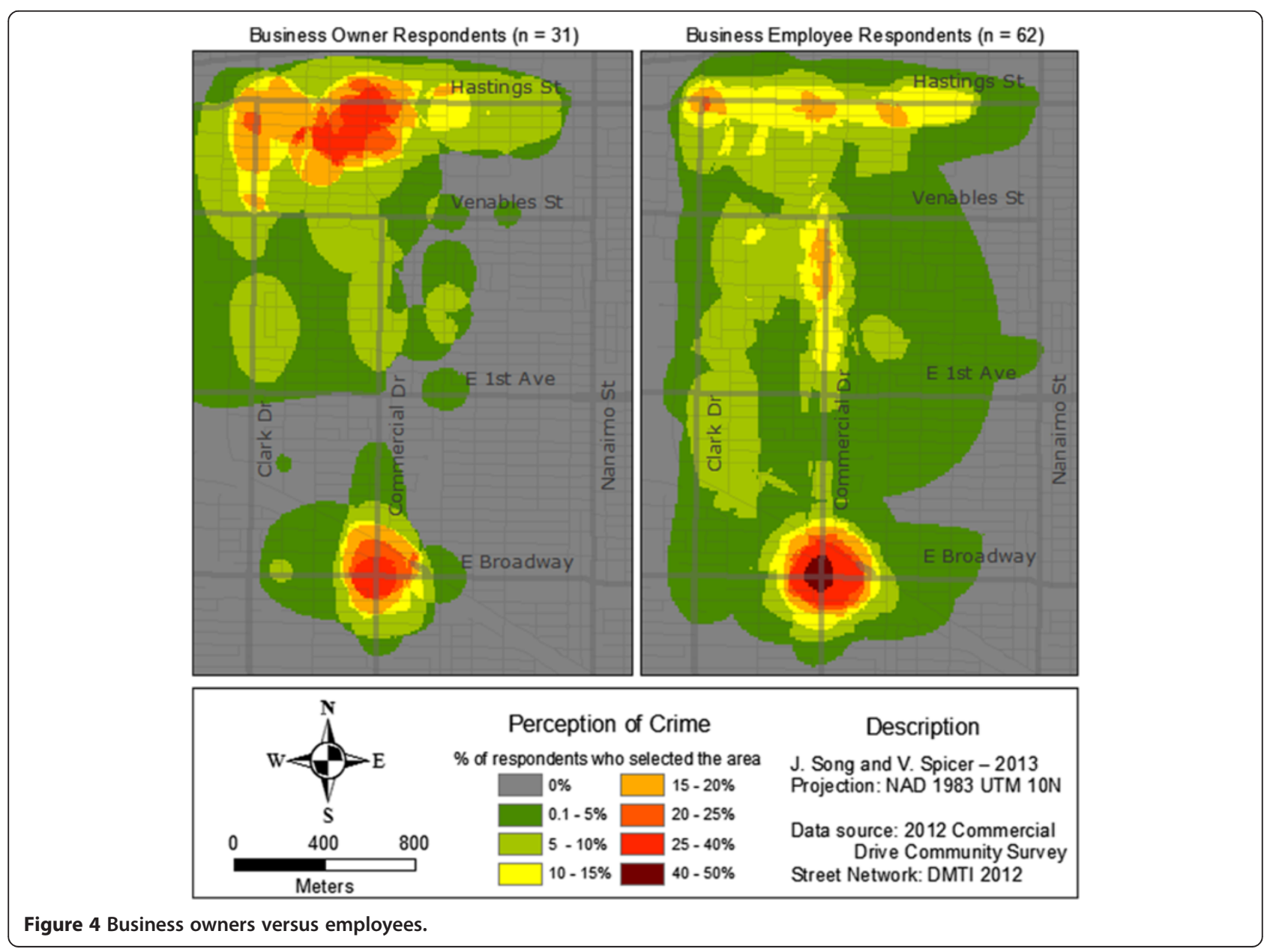


whereas business off Commercial Drive on average are larger drawn polygons 235,565 square meters. It is also interesting that the distance between the respondent's business and the respondent's drawn polygon is closer from businesses on Commercial Drive - 651.2 meters between the business and the drawn polygon - versus 704.4 meters for businesses off Commercial Drive.

Figure 4 displays the perceptual patterns for business owners and employees. These two vary significantly with employees more focused on the transit hub and business owners selecting two predominant areas. As well, employees pick a more concentrated area likely associated to generalized movement patterns linked to mass transportation. While business owners appear to have a perceptual pattern more likely associated with vehicle-based transportation. Future perception survey should take into account primary transportation mode as part of the data collection.

Figure 5 explores the difference between male and female respondents. In this case, females have a much more condensed perception of crime located at the Skytrain station. Over $40 \%$ of these respondents selected a very small area at the intersection of Broadway and Commercial Drive where this transportation hub is located. Males, on the other hand, seem to have a more diffused perception of crime and the two hotspot split between the northern section and the Skytrain station. Several hypotheses could explain these differences that could be further researched. The northern section of the study area is predominantly industrial and would not be travelled as much on foot. Given this is a business study, the male respondents might be more likely employed in this area, utilize vehicles to attend and therefore familiar with the crime dynamics in this location. Whereas the female respondents more likely to be employed in the businesses on Commercial Drive and therefore more likely to access the Skytrain. Future iteration of this study should include questions about mode of transportation in order to further explore this hyposthesis.

A second hypothesis may be related to the formation of safety templates and gender differences that can occur in this formation. Safety templates are formed during routines activities and experiences with crime and disorder cues. These experiences can be varied and include real experiences, perceived risk, and can be supplemented by information gathered in the media or through social ties. For the females in this sample, the Skytrain station
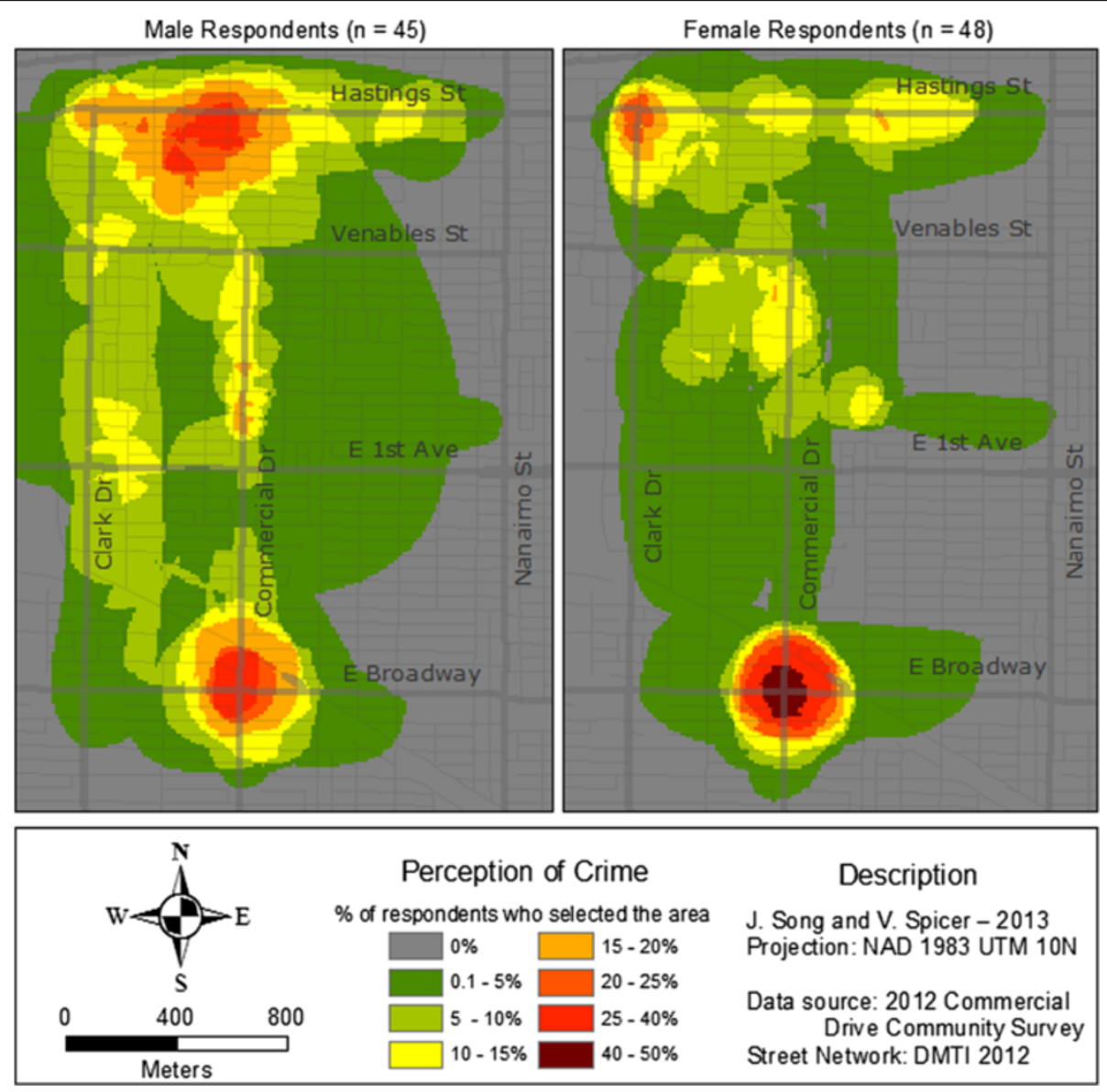

Figure 5 Males versus females. 
may be a very defined crime generator with intense resonance. Therefore this location may emanate very strongly in the aggregate and demonstrate how locations can become fixed within a safety template. Future research could delve into these differences to explore how different locations or landmarks can factor into the gendered formation of safety templates.

Figure 6 compares respondents who were victims of property crime to those who were victims of personal crime. These are two different perceptual patterns. Respondents who were victims of property crime continue to focus on the Skytrain station. Comparatively, victims of personal crime have more diffused perception likely associated to their personal experience. It should be noted that very few respondents $(n=18)$ were victims of personal crime.

Finally, Figure 7 demonstrates another method to visualize these results. Since the raster function is utilized in the analysis, it is possible to create an accurate street chart to further explore variations in perception. The raster size of 10 meters by 10 meters allows for an accurate interpretation of results at the neighborhood level. This Figure 7 clearly shows that significant difference between these two business communities. Businesses on Commercial Drive are much more focused on the Skytrain station and the main shopping area. Whereas business off Commercial Drive appear more concerned with the northern section of the studies area.

\section{Conclusion}

Heightened perception of crime can have a negative impact on business in general and reduces feelings of security for business owners, employees and clients. The results in this study show a heightened perception of crime that is both proximal and distal. These two distinct business communities select a proximal area close to the majority of the businesses in the sample while at the same time selecting a distal area located at a mass transportation hub. Future research should focus on furthering this spatial analysis by looking at how these two business communities differ in their experience of disorder. In particular, the responses from the 30 questions about crime and disorder included in this survey could be compared and used to further understand the perceptual patterns.

This study supports the theoretical propositions founded in environmental criminology. Indeed, proximal perception

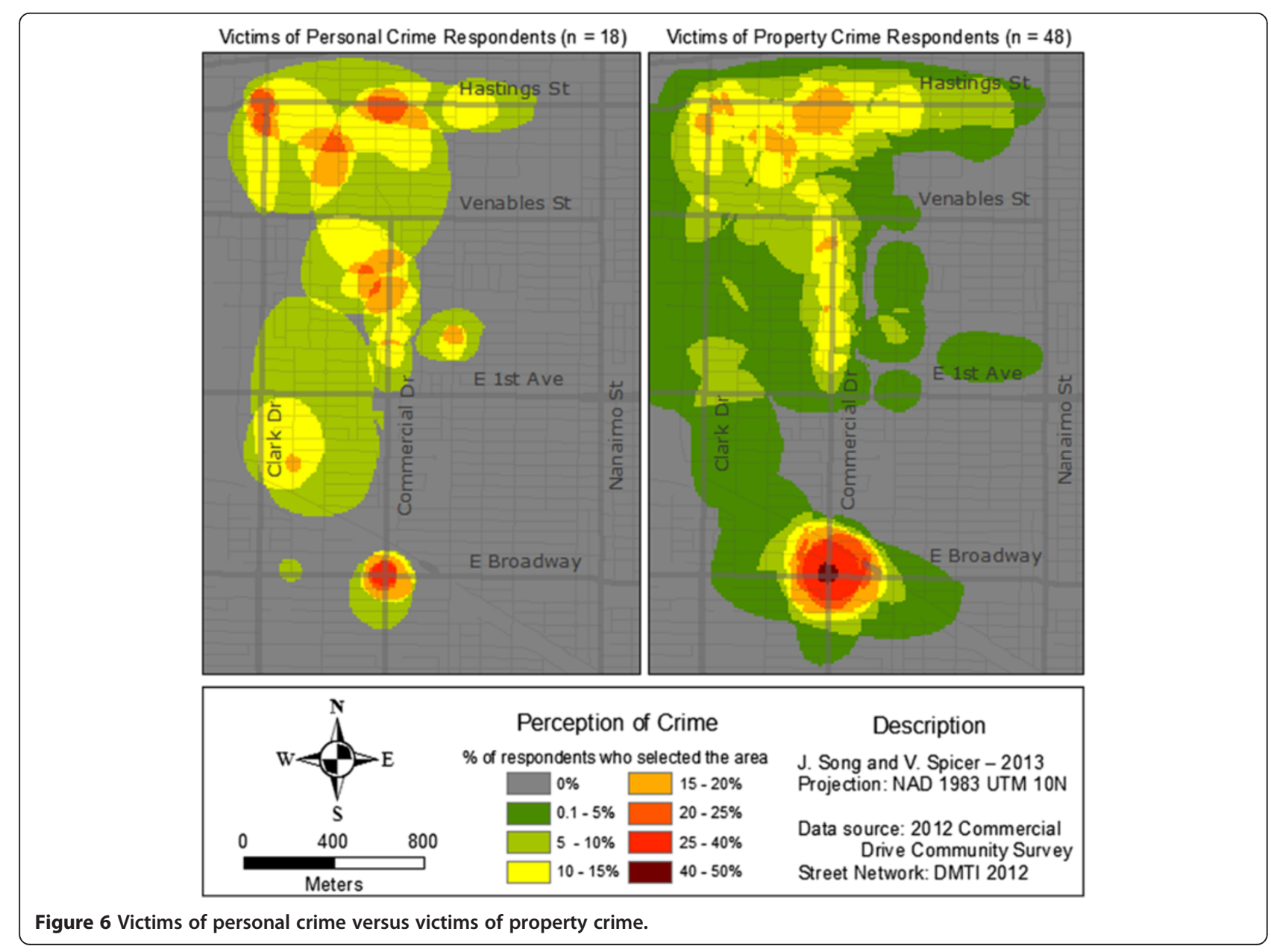




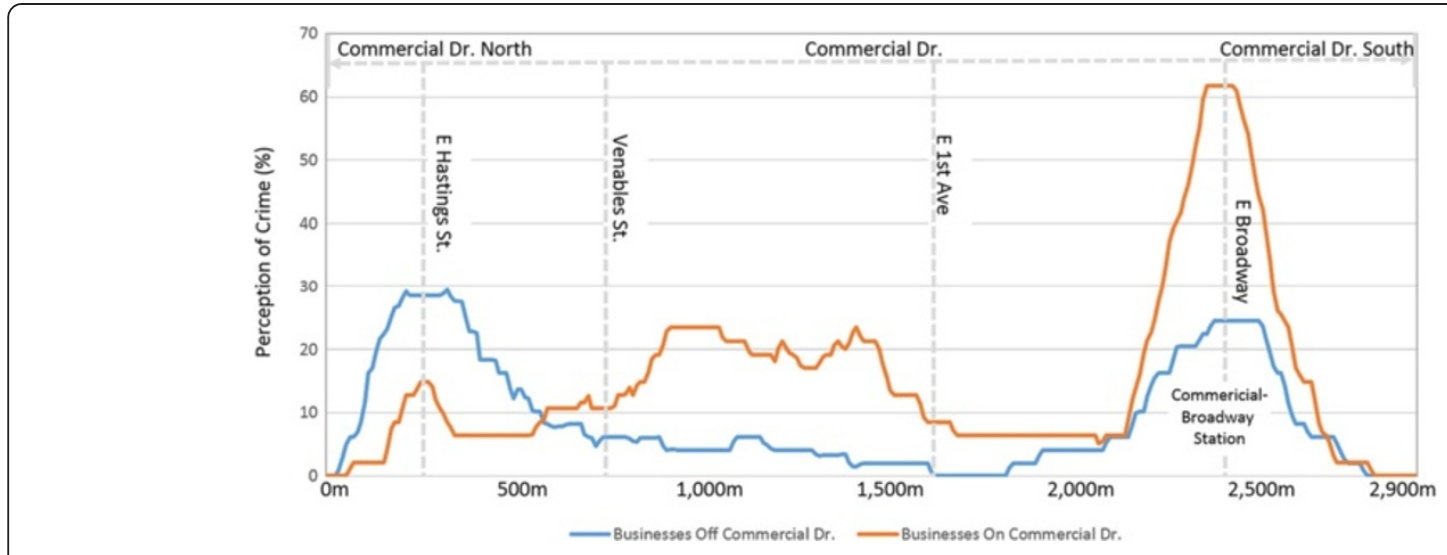

Figure 7 Perception chart.

is individualize and linked to cues in the environment while distal perception associated with routine activities that form aggregate patterns of perception as related to the generalized movement of citizens in the urban domain. In order to enhance feelings of security within the business community, civic agencies need to optimize their strategies along well-travelled routes while also addressing the local needs of micro business communities. These strategies should include measures that mitigate the effects of disorder associated with mass transportation that also impact pedestrian based streets such as Commercial Drive.

In particular, the concept of safety templates is introduced in this paper. These varied perceptual patterns indicate that variations can be linked to a number of factors including the location of the business, the work function in the business, gender, prior victimization as well as other factors not included in this instrument. Future research needs to further define and explore the concept of safety templates as this could assist in formalizing this concept and transforming it into a preventative strategy that can be shared within the business community. The concept of safety templates can be improved on in future research to determine the relationship between place of residence and place of employment. As well, the respondents' characteristics could help in describing the various factors impacting the formation of safety templates.

This study shows how two very distinct patterns emerge with one micro area linked to the businesses surveyed on Commercial Drive where there is high pedestrian traffic, and the other area connected to an industrial zone where other problems create a more diffused sense of perception. Future research will focus on extracting more precise information on the areas selected, including the associated movement patterns of the person drawing the map, additional testing of the fear generating cues, and the relationship of these factors with actual crime in the area. This will help to further elucidate environmental factors that trigger a heightened perception of crime and with further testing could lead to a business fear generation measurement tool to be used by police and civic agencies.

\section{Acknowledgements}

We are grateful to the support from the Grandview-Woodland Community Policing Centre for implementing this business survey and in particular Baljit Bhullar who was integral during the data collection phase of this project.

Received: 20 May 2014 Accepted: 2 September 2014

Published online: 26 September 2014

\section{References}

1. J Flatley, S Moley, J Hoare (eds.), Perceptions of Anti-Social Behavior: Findings from the 2007/08 British Crime Survey (Home Office, London, 2008)

2. BK Scarborough, TZ Like-Haislip, KJ Novak, WL Lucas, LF Alarid, Assessing the relationship between individual characteristics, neighborhood context, and fear of crime. J. Crim. Justice 38(4), 819-826 (2010)

3. P Smith, TL Phillips, RD King, Incivility: The Rude Stranger in Everyday Life (Cambridge University Press, Cambridge, 2010)

4. N Yavuz, EW Welch, PS Srijaj, Individual and Neighborhood determinants of perceptions of bus and train safety in Chicago: An application of hierarchical linear modeling. Trans. Res. Rec. 2034, 19-26 (2007)

5. JM Gau, TC Pratt, Revisiting broken windows theory: examining the sources of the discriminant validity of perceived disorder and crime. J. Crim. Justice 38(4), 758-766 (2010)

6. A Park, Modeling the Role of Fear of Crime in pedestrian Navigation (Simon Fraser University, 2008). PhD dissertation

7. A Park, J Clare, V Spicer, PL Brantingham, T Calvert, G Jenion, Examining contextspecific perceptions of risks: Exploring the utility of "human-in-the-loop" simulation models for criminology. J. Exp. Criminol. 8(8), 29-47 (2012).

8. RJ Sampson, SW Raudenbush, Seeing disorder: neighborhood stigma and the social construction of "broken windows". Soc. Psychol. Q. 67, 319-342 (2004)

9. T Armstrong, C Katz, Further evidence on the discriminant validity of perceptual incivilities measures. Justice Q. 27(2), 280-304 (2009)

10. KF Ferraro, Fear of Crime Interpreting Victimization Risk (State University of New York Press, Albany, New York, 1995)

11. JH Ratcliffe, A temporal constraint theory to explain opportunity-based spatial offending patterns. J. Res. Crime. Delinquency 43(3), 261-291 (2006)

12. J Robinson, L Goridano, M Andresen, B Kinney (eds.), Spatial Interplay: Interaction of Land Uses in Relation to Crime Incidents Around Transit Stations. Patterns, Prevention, and Geometry of Crime (Routledge, London, 2011)

13. RJ Sampson, SW Raudenbush, Systematic social observation of public spaces: a new look at disorder in urban neighborhoods. AJS 105(3), 603-651 (1999)

14. G Valentine, Living with difference: reflections on geographies of encounter. Prog. Human Geogr. 32(3), 323-337 (2010)

15. JL Worrall, The discriminant validity of perceptual incivility measures. Justice Q. 23(3), 360-383 (2006) 
16. E Brunswick, The Conceptual Framework of Psychology. International Encyclopedia of Unified Science, Vol. 1(10) (The University of Chicago Press, Chicago, 1952)

17. S Chainey, J Ratcliffe, GIS and Crime Mapping (Wiley, Hoboken, NJ, 2005)

18. T Satur, ZQ Liu, A contextual fuzzy cognitive map framework for geographic information systems. IEEE Trans. Fuzzy Syst. 7(5), 481-494 (1999)

19. S Chainey, Tompson, S Uhlig, The utility of hotspot mapping for predicting spatial patterns of crime. Secur. J. 21, 4-28 (2008)

20. V Spicer, The Geometry of Fear: An Environmental Perspective on Fear and the Perception of Crime (Simon Fraser University, 2012). PhD Dissertation

21. PJ Brantingham, PL Brantingham, Notes on the geometry of crime, in Environmental Criminolgy, ed. by PJ Brantingham, PL Brantingham (Waveland Press, Prospect Heights, 1981)

22. LA Cohen, M Felson, Social change and crime rate trends: a routine activity approach. Am. Sociol. Rev. 44, 598-608 (1979)

23. AD Newton, Crime on public transport: 'Static' and 'non-static' (moving) crime event. West. Criminol. Rev. 5(3), 25-42 (2004)

24. DB Cornish, RV Clarke (eds.), The Reasoning Criminal: Rational Choice Perspectives on Offending (New York Springer-Verlag, New York, 1986)

25. N Yavuz, EW Welch, Addressing fear of crime in public space: gender differences in reaction to safety measures in train transit. Urban Stud. 47(12), 2491-2515 (2010)

26. PJ Brantingham, PL Brantingham, A theoretical model of crime site selection, in Crime, Law and Sanction, ed. by M Krohn, RL Akers (Sage Publications, Beverly Hills, California, 1978), p. 1978

27. J Song, V Spicer, P Brantingham, Richard Frank, Crime Ridges: Exploring the relationship between crime attractors and offender movement. Conference Proceedings - European Intelligence and Security Informatics Conference EISIC (2013), (IEEE, Uppsala, Sweden, 2013)

28. PL Brantingham, PJ Brantingham, Environment routine and situation: toward a pattern theory of crime. Adv. Criminol. Theor. 5, 259-294 (1993)

29. PJ Brantingham, PL Brantingham, Understanding and controlling crime and fear of crime: conflicts and trade-offs in crime prevention planning, in Crime Prevention at a Crossroads, ed. by SP Lab (Anderson Publishing Co., Cincinnati, Ohio, 1997), p. 1997

doi:10.1186/s13388-014-0014-4

Cite this article as: Spicer et al:: Bridging the perceptual gap: variations in crime perception of businesses at the neighborhood level. Security Informatics 2014 3:14.

\section{Submit your manuscript to a SpringerOpen ${ }^{\circ}$ journal and benefit from:}

- Convenient online submission

- Rigorous peer review

- Immediate publication on acceptance

- Open access: articles freely available online

- High visibility within the field

- Retaining the copyright to your article

Submit your next manuscript at $\gg$ springeropen.com 